\title{
Parametric numerical studies on the dynamic response of unreinforced masonry structures
}

\author{
C. Chácara \& P. B. Lourenço \\ University of Minho, Guimarães, Portugal \\ B. Pantò, F. Cannizzaro \& I. Caliò \\ University of Catania, Sicily, Italy
}

\begin{abstract}
The prediction of the dynamic response of Unreinforced Masonry Structures (URMS) is a very complex task, since it is governed by material degradation and cyclic hysteric behaviour. Procedures based on nonlinear static analyses have been proposed for the seismic assessment of URMS, without properly considering hysteretic energy dissipation during the dynamic response. Even though dynamic nonlinear analyses provide satisfactory simulations of the seismic response, its application requires considerable computational effort and high user expertise for the accurate definition of the material properties, making it unsuitable for practical applications. However, simplified macro-element strategies, capable of simulating in-plane and outof-plane nonlinear responses, could represent a satisfactory engineering solution in the dynamic context. In this study the nonlinear static and dynamic in-plane behaviour of URMS was assessed by means of plane discrete models. The preliminary numerical investigation evidenced the need to define suitable hysteric constitutive laws for reliable nonlinear dynamic analyses of URMS.
\end{abstract}

\section{INTRODUCTION}

The study of unreinforced existing masonry structures (URMS) in the nonlinear field is a debated topic in the scientific community. In the last decades many efforts have been devoted towards the formulation of numerical models able to catch the nonlinear response of such structures in an effective way.

Two main modelling approaches have been addressed by the researchers: the accurate and rigorous ones, and the so-called simplified models.

Accurate models aim at providing rigorous solutions for the assessment of the nonlinear response of existing masonry structures. They are typically based on a nonlinear finite element approach, (Lourenço, 1996). Nevertheless, the adoption of such rigorous methods is generally confined to the academic environment because of the expertise required for the interpretation of the results and because of the huge computational effort often required. Furthermore, they are generally employed only for detail models to calibrate more simplified models. Very few cases of complete buildings are available in the literature, (Lourenço, 1996).

On the other hand, the need of making available to practitioners reliable tools for the static and seismic assessment of real URMS has led many researchers to propose models based on simplified hypotheses, able to simulate the overall behaviour of real buildings. Many of them are based on the well know equivalent frame approach, (Brencich et al., 1998, Magenes and Della Fontana, 1998). Some of them are instead based on bi-dimensional macroelements, (D'Asdia and Viskovic, 1996, Caliò et al., 2012). The main advantage of these proposals is the capability of assessing the nonlinear response of complete buildings with a limited computational effort, thus making them suitable also for practical purposes.

In spite of the wide selection of rigorous and simplified models, their application is generally limited to the static context by means of monotonic static pushover analyses. However the cyclic constitutive behaviour plays a crucial role in the actual response of existing buildings. This is even more important for masonry buildings where different damage mechanisms may lead to very different energy dissipation and strength degradation. In order to catch the effectively the cyclic behaviour of the masonry media, nonlinear static cyclic analyses, or full nonlinear dynamic simulations are needed. However, only very few examples of nonlinear dynamic analyses on existing masonry buildings are available in the literature, (Mendes and Lourenço, 2014).

In this paper, a bi-dimensional macro-element previously introduced for the study of the in-plane behaviour of existing masonry buildings, Caliò et al. (2012), is employed for the first time in the dynamic context. First, a validation of the consistency of the model is provided in the nonlinear static context by 
means of pushover analyses and in the linear dynamic context by means of the computation of the fundamental frequencies and modes. The comparisons are made with a finite element approach implemented in the code DIANA (TNO, 2013).

Then, nonlinear time histories are performed on simple structures, and the results are compared and discussed with those obtained with nonlinear static analyses. Finally, several parametric analyses are performed in order to investigate the influence of the mesh and the hysteretic dissipation on the dynamic response of such structures.

\section{MACRO-ELEMENT MODELLING APPROACH}

In this section a synthetic description of the adopted modelling approach is addressed, Caliò et al. (2012). The adopted model can be considered as a part of the wider selection of the bi-dimensional macroelements. The considered model is based on a simple mechanical scheme made of nonlinear unidirectional springs (NLinks) and rigid bars, which is briefly described in the first subsection. The effectiveness of the model depends on the calibration of those NLinks; the calibration procedures are synthetically described in the second subsection of this paragraph.

\subsection{Mechanical scheme}

The macro-element modelling approach introduced by Caliò et al. (2012) aims at the seismic assessment of masonry structures for engineering applications. The in-plane response of masonry structures is conducted by means of two-dimensional panels (macroelements) composed by four rigid edges connected by four hinges and two diagonal nonlinear links. Adjacent panels are connected by means of interface elements composed by a discrete distribution of orthogonal and longitudinal NLinks. The mechanical scheme of this macro-element modelling approach is illustrated in Figure 1.
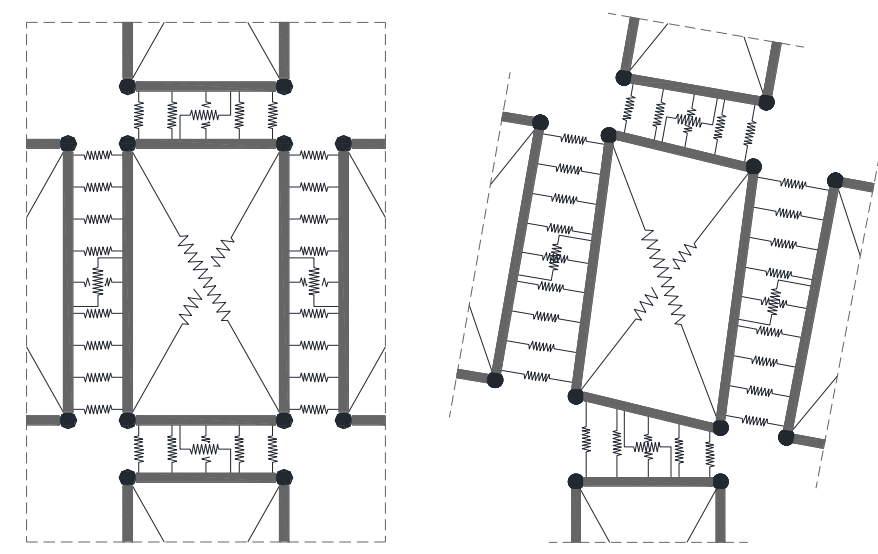

Figure 1. Mechanical scheme of the plane macro-element proposed by Caliò et al. (2012).
This bi-dimensional macro-element model is capable of simulating the main in-plane failure mechanisms of masonry structures, namely flexural, sheardiagonal, and shear-sliding. The flexural failure mechanism is related to the rocking of masonry in its own plane, in which the loss of the bearing capacity comes as a result of the crushing of the panel in the compressive zone together with the progressive rupture of the element in the zone which undergoes tension. The flexural behaviour is coupled with the axial response and it is governed by the orthogonal NLinks at the interface elements (see Figure 2a). The occurrence of the shear-diagonal failure mechanism is caused by the loss of bearing capacity due to the formation of diagonal cracks from excessive shear strain deformations and limited tensile strength. The diagonal NLinks aim at simulating the shear response of masonry structures as illustrated in Figure 2b. Finally, the shear-sliding failure mechanism is related to the in-plane sliding of masonry in which the loss of bearing capacity results from the formation of cracks parallel to the bed joints and it mainly occurs in presence of low values of the axial load. This failure mechanism is governed by the additional longitudinal nonlinear Link at the interface element as shown in Figure 2c.

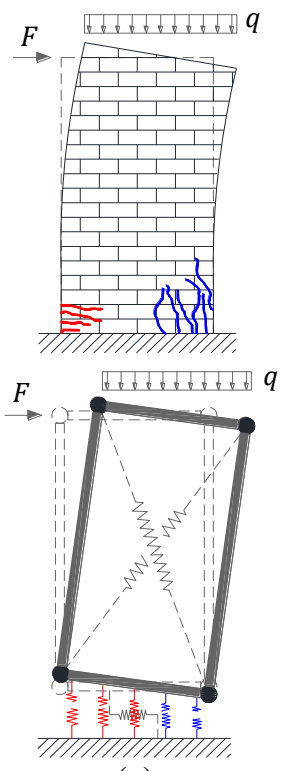

(a)

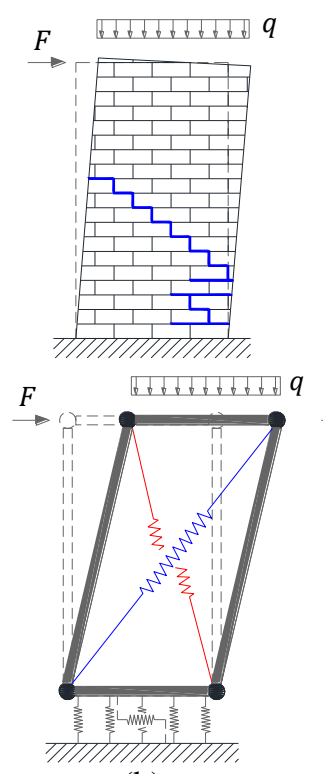

(b)

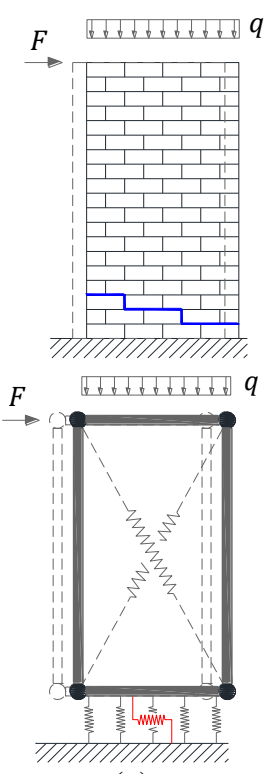

(c)
Figure 2. Simulation of main in-plane failure mechanisms of masonry structures.

\subsection{Fiber calibration procedure}

The definition of the mechanical properties of the nonlinear Links is based on a fiber calibration procedure which takes into consideration well known masonry material parameters. The calibration of the flexural response, concentrated at the interface element, is conducted by establishing an equivalence between two orthogonal Links in series corresponding to two adjacent panels (see Figure 3). These 
Links are endowed with an elasto-plastic constitutive law with limited deformability. The calibration of its stiffness requires the determination of the axial rigidity of each orthogonal Link which is characterized by the influence area, the Young's modulus $E$ and the thickness of the corresponding panel. The couple of nonlinear Links in series from two adjacent panels are subsequently replaced by a single equivalent Link. In order to simulate the orthotropic behaviour of the material, vertical and horizontal interfaces are calibrated separately based on the material parameters of each direction.
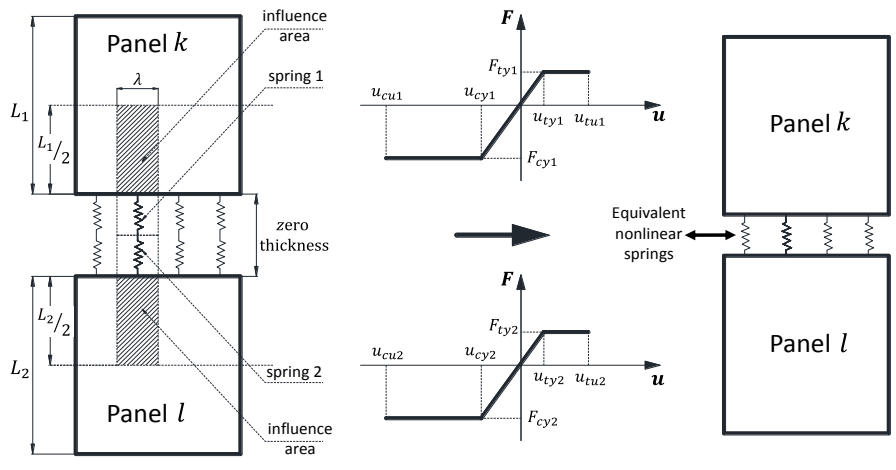

Figure 3. Mechanical scheme of the plane macro-element proposed by Caliò et al. (2012).

The calibration of the shear-diagonal stiffness is obtained by establishing an elastic equivalence between the macro-element and the masonry wall as a continuum medium subjected to a shear force $V$ with pure shear deformability $\delta$ as illustrated in Figure 4. This continuum plate is defined by the shear modulus $G$, the transversal area $A_{t}$, the height $h$ and the base $b$. The determination of the shear strength of the macro-element may be alternatively based on two yielding approaches, namely the Mohr-Coulomb and the Turnsek and Cacovic criterion. The latter criteria are based on the dependence on the current axial force, which is inferred by the transversal forces of the four interfaces around each panel. The corresponding ultimate displacement and shear strength of each diagonal Link is obtained from the mechanical properties of the material depending on the adopted shear resistance criteria.

Finally, the calibration of the shear-sliding response is given by a rigid plastic constitutive law at the longitudinal Link governed by a Mohr-Coulomb yielding surface. The axial force acting on each sliding nonlinear Link is inferred from the transversal action of the corresponding interface.

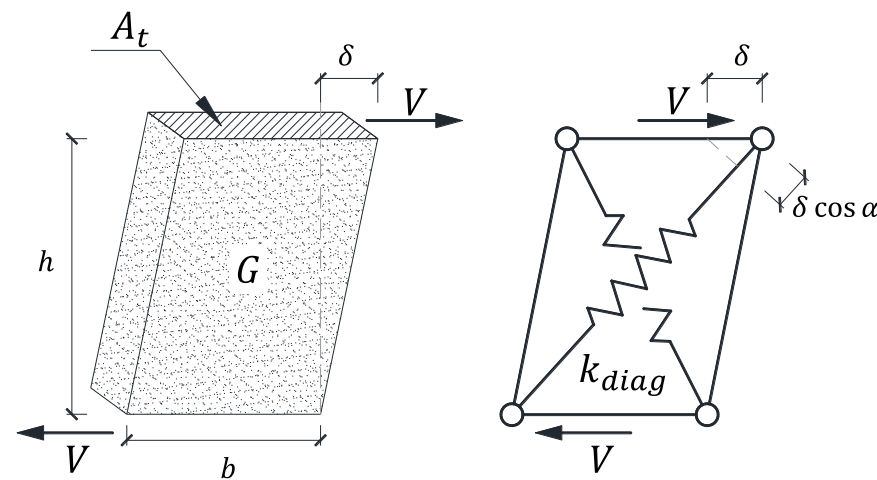

Figure 4. Mechanical scheme of the plane macro-element proposed by Caliò et al. (2012).

\section{CYCLIC CONSITUTIVE MODELS}

Aiming at simulating the dynamic behaviour of masonry structures, taking into consideration the different loading and unloading cycles as well as the dissipated hysteretic energy, the response of each of the in-plane failure mechanisms, namely flexural, sheardiagonal, and shear-sliding (reported in section 2), is governed by a specific cyclic constitutive law.

In the case of the flexural response, the nonlinear orthogonal Links at the interface elements are governed by a tri-linear constitutive model according to a Takeda (Takeda et al., 1970) model, in which the hysteretic cycles are characterized by a coefficient defined as $\beta$ which rules the unloading stiffness. This unloading coefficient presents a value that ranges between 0 and 1 . In particular, the unloading stiffness $k_{o}$ of each link is given by:

$k_{u}=k_{i}+\left(k_{o}-k_{i}\right) \beta$

When $\beta=1$ the unloading branch is oriented to the origin $\left(k_{o}\right)$; on the other hand, when $\beta=0$ the unloading stiffness is equal to the initial stiffness $\left(k_{i}\right)$. Once the unloading branch is over, the response of the nonlinear orthogonal Links in the reloading phase (that is loading in the opposite direction) is oriented to the maximum value of the backbone curve achieved in the previous cycle as illustrated in Figure 5.

Furthermore, for the shear-diagonal response, the nonlinear diagonal Links are still governed by a Mohr-Coulomb or the Turnsek and Cacovic yielding criterion. In this case, the cyclic behaviour follows the same approach as the orthogonal Links, presenting a $\beta$ coefficient for the unloading, and the reloading branch oriented to the maximum achieved displacement. 


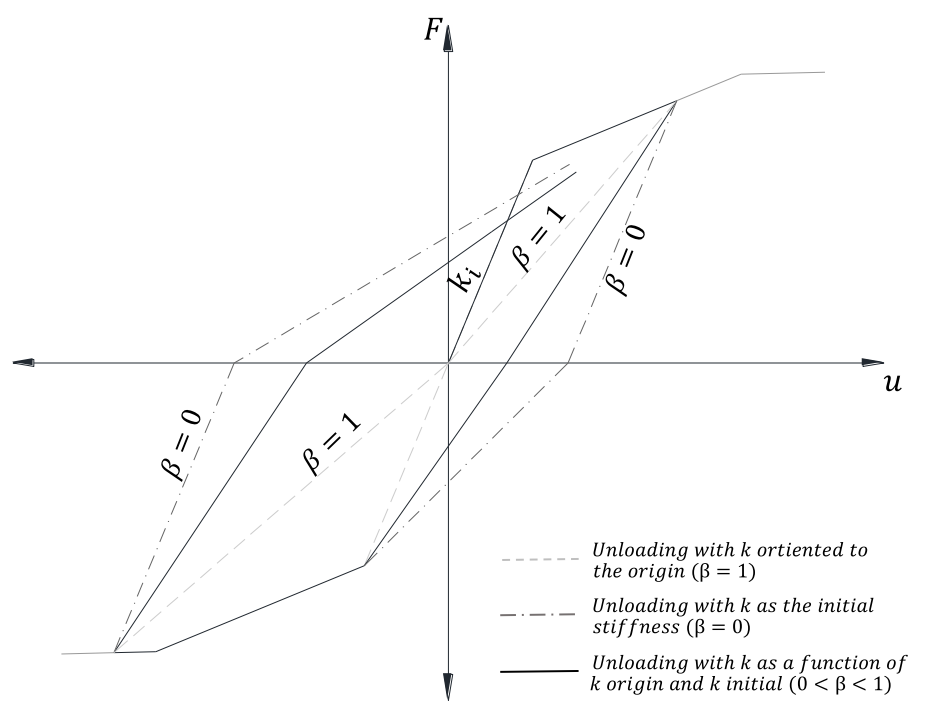

Figure 5. Cyclic constitutive law governing the flexural response of the macro-element approach.

Finally, the cyclic response of the nonlinear longitudinal Link that simulates the shear-sliding failure mechanism is governed by a Mohr-Coulomb yielding criterion. However, in this case, the cyclic response follows an elasto-perfectly plastic model, in which the unloading and reloading branches are characterized by the initial stiffness as illustrated in Figure 6.

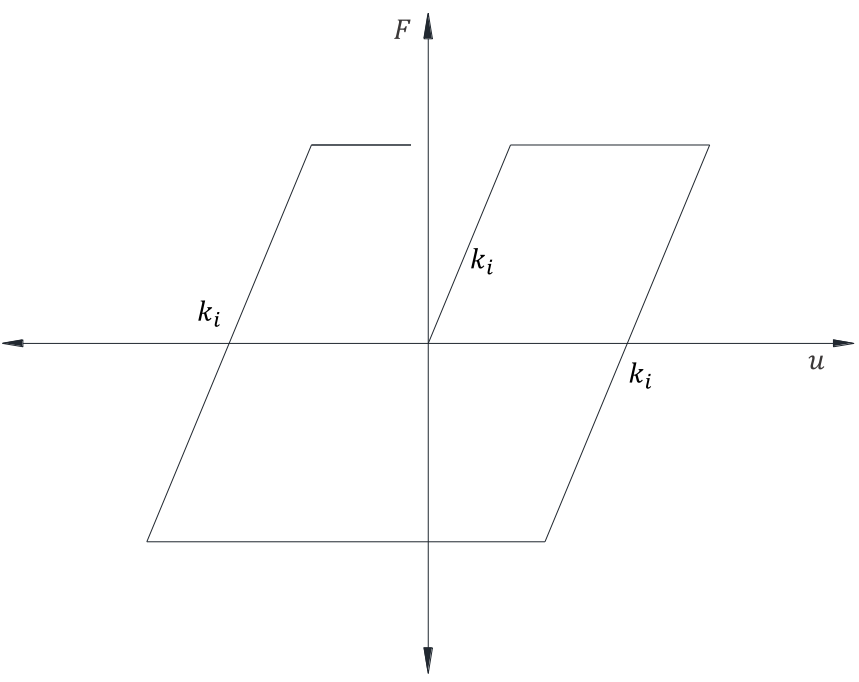

Figure 6. Cyclic constitutive law governing the sliding Link.

\section{VALIDATION OF MACRO-ELEMENT MODEL}

This macro-element modelling approach has been implemented in the computer code HiStrA (Historic Structure Analysis) (HISTRA s.r.1, 2015). The validation of this modelling approach was conducted by comparing the responses of a set of macro-element models subjected to static loading and their corresponding equivalent finite element models. Furthermore, a dynamic validation in the linear field is reported by comparing the dynamic characterization derived from the macro-element and the finite element approaches.

For the static validation, each macro-element model is composed by a single panel presenting a fixed restraint at the base and limiting the rotation at the top (as illustrated in Figure 7). The equivalent finite element model also consists on a single panel with a detailed mesh refinement implemented in the software DIANA (TNO, 2013). Each model is characterized by a different slender ratio so that its response is mainly governed by a specific failure mechanism, namely flexural and shear, respectively. For the simulation of the flexural response, this ratio has value of 2, whereas for the shear response a value of 0.67 . The squat model is characterized by a single panel while the slim model is discretized with 8 panels with the same geometry $(1.5 \times 1.5 \mathrm{~m})$. Further details of the geometric and material parameters are summarized in Table 1. The Cacovic criterion for the diagonal shear mechanism has been adopted in the numerical simulations.

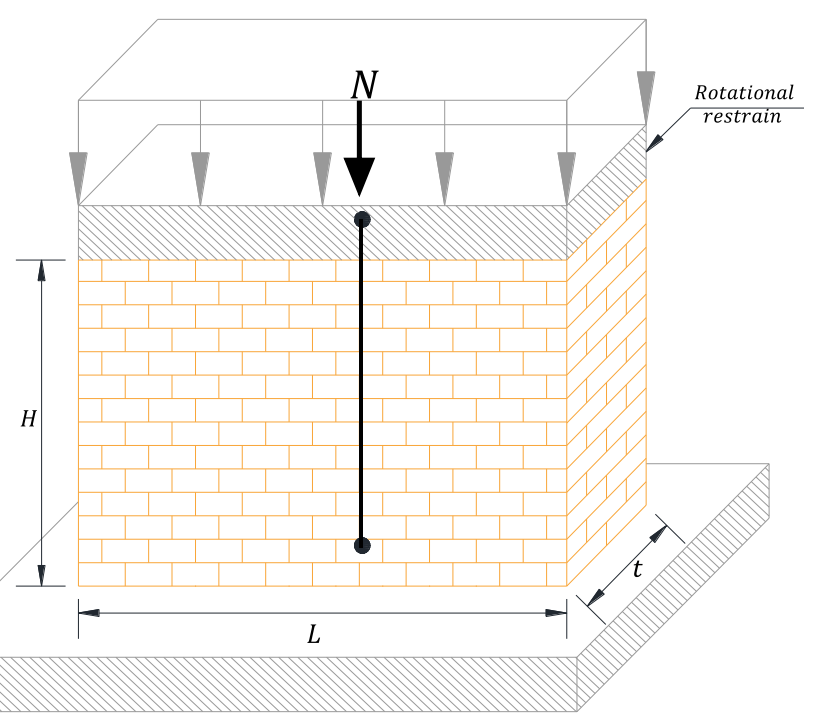

Figure 7. Layout of the considered models

Table 1. Geometric and material properties of the macro-element model

\begin{tabular}{cccccccc}
\hline & \multicolumn{3}{c}{ Geometric de- } & & \multicolumn{3}{c}{ Mechanical parameters } \\
\cline { 2 - 7 } & $\begin{array}{c}t \\
(\mathrm{~m})\end{array}$ & $\begin{array}{c}B \\
(\mathrm{~m})\end{array}$ & $\begin{array}{c}H \\
(\mathrm{~m})\end{array}$ & $\begin{array}{c}E \\
(\mathrm{MPa})\end{array}$ & $\begin{array}{c}G \\
(\mathrm{MPa})\end{array}$ & $\begin{array}{c}f_{c} \\
(\mathrm{MPa})\end{array}$ & $\begin{array}{c}f_{t} \\
(\mathrm{MPa})\end{array}$ \\
\hline Slim & 0.6 & 3.0 & 6.0 & 870 & 348 & 1.0 & 0.1 \\
Squat & & & 2.0 & & & & 0.067 \\
\hline
\end{tabular}

The static validation consisted on the assessment of the maximum load capacity of the models subjected initially to a vertical load and subsequently to an incremental concentrated horizontal load applied at the top of the panel. For this purpose, different values of axial load were taken into consideration. Figure 8 illustrates the relation between the axial load and the ultimate base shear for both the squat 
and slim models. It is possible to observe that the flexural response corresponding to the macroelement and finite element modes are in good agreement. On the other hand, the shear response presents some differences since in the macroelement (discrete) model, the shear and flexural responses are governed by different mechanical properties, whereas in the finite element model, the two responses are coupled and governed by the tensile strength. It is worth noting that the shear strength for the macro-element model has been adopted as 1.5 times the tensile strength. According to this assumptions, it is also possible to observe that with low values of axial load, there is a good agreement between the two models. A more significant difference is evidenced with higher values of axial load. However, the maximum error obtained from these analysis was $15 \%$.

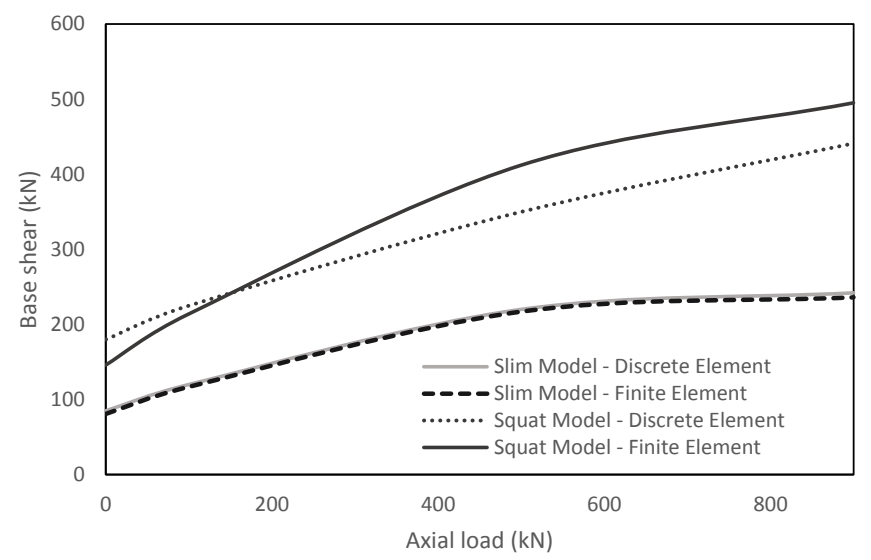

Figure 8. Maximum strength vs vertical action

In addition, a comparison in terms of deformed shapes and crack pattern was also performed from the static analyses. It was possible to accurately reproduce a similar deformed shape as illustrated in Figure 9. It can be observed that the slim panel is governed by a rocking failure mode presenting damage on the corners due to yielding in tension and compression. In the case of the squat panel, the failure mode is governed by a shear response. In the case of the macro-element model, the nonlinearity was concentrated mainly on the diagonal Links. However some orthogonal Links presented a nonlinear behaviour. This response was also reproduced in the finite element model (diagonal cracking and concentration of damage in two opposite corners).

Furthermore for a specific value of the vertical action, i.e. $500 \mathrm{kN}$, the pushover curves relative to the slim and squat panels are reported. The comparisons with the results provided with the nonlinear finite element approach are in good agreement both in terms of initial stiffness and ultimate load.
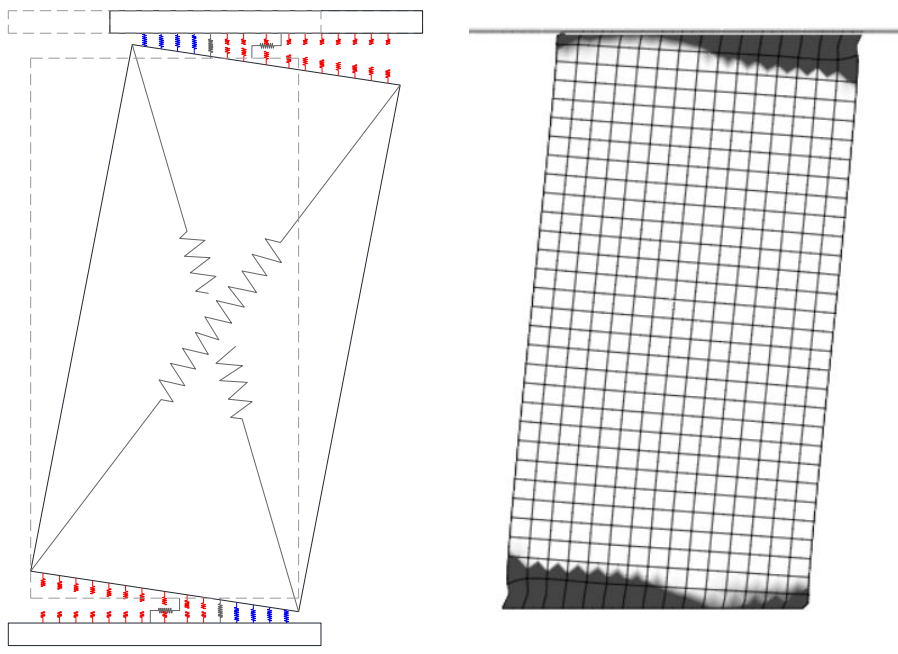

(a)

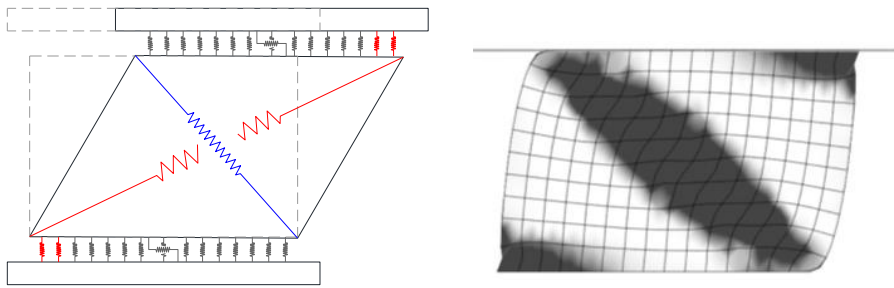

(b)

Figure 9. Failure mechanisms: (a) slim panel and (b) squat panel.

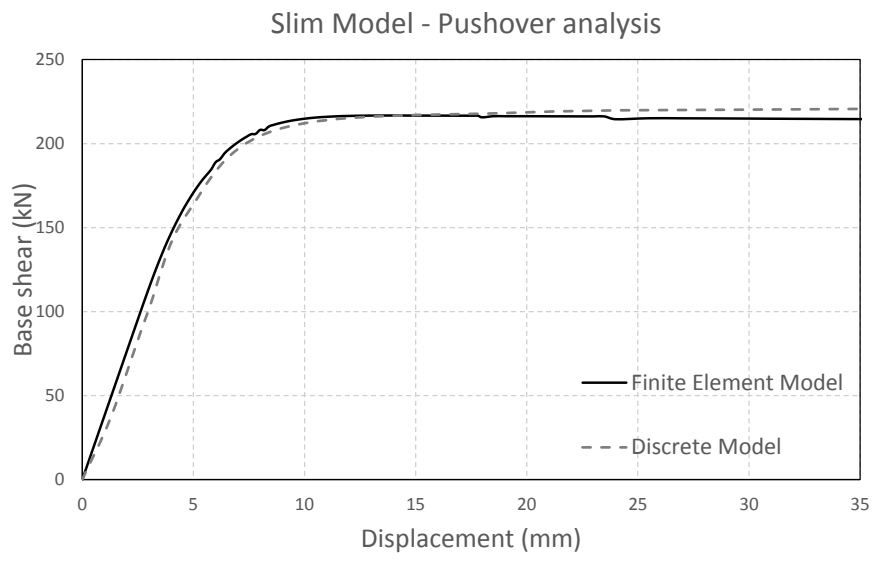

(a)

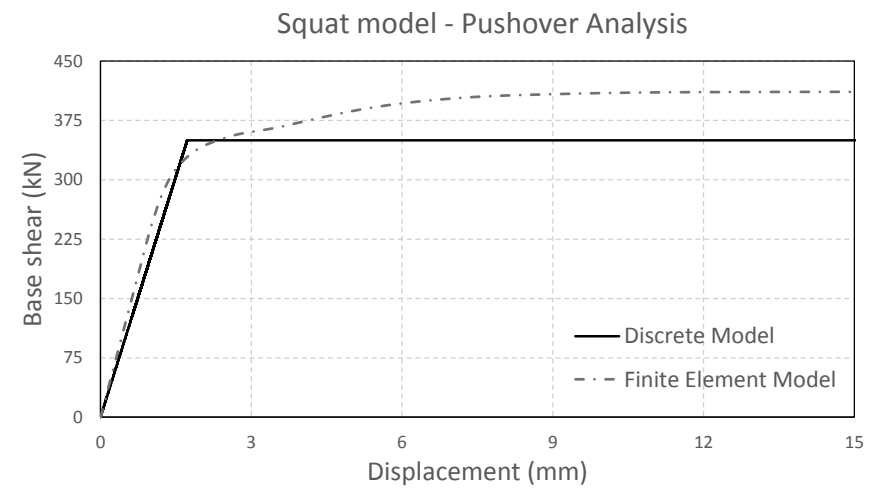

(b)

Figure 10. Pushover curves of the (a) slim and (b) squat models for a specific value of the axial load: comparison between macro-element and nonlinear finite element approaches.

The dynamic validation was performed by means of the comparison of the dynamic properties for the models already studied in the static context. It was 
possible to determine a good agreement in terms of natural frequencies between the finite element and the discrete element models. The results in terms of fundamental frequencies corresponding to the first three modes are reported in Table 2 together with the relative error for both the considered models.

Table 2. Comparison of dynamic properties

\begin{tabular}{ccccccc}
\hline & \multicolumn{3}{c}{ Slim Model } & \multicolumn{3}{c}{ Squat Model } \\
\cline { 2 - 7 } Mode & $\begin{array}{c}\text { FE } \\
\text { Model } \\
(\mathrm{Hz})\end{array}$ & $\begin{array}{c}\text { Discrete } \\
\text { Model } \\
(\mathrm{Hz})\end{array}$ & $\begin{array}{c}\text { Error } \\
(\%)\end{array}$ & $\begin{array}{c}\text { FE } \\
\text { Model } \\
(\mathrm{Hz})\end{array}$ & $\begin{array}{c}\text { Discrete } \\
\text { Model } \\
(\mathrm{Hz})\end{array}$ & $\begin{array}{c}\text { Error } \\
(\%)\end{array}$ \\
\hline $1^{\text {st }}$ & 4.06 & 4.65 & 12.7 & 11.2 & 11.68 & 4.1 \\
$2^{\text {nd }}$ & 10.8 & 12.4 & 12.5 & 20.37 & 20.41 & 0.2 \\
$3^{\text {rd }}$ & 37.7 & 38.3 & 1.6 & 140 & 138.6 & 1.0 \\
\hline
\end{tabular}

\section{DYNAMIC ANALYSIS AND PARAMETRIC STUDY}

The non-linear dynamic analyses by using the proposed discrete macro-model approach have been performed considering a scaled ground motion corresponding to the New Zealand earthquake in 2011. The analyses have been performed by means of the average acceleration Newmark method. A damping ratio of 5\% was defined for these analyses and it was based on a Rayleigh approach. In addition, the assessment of the dissipated hysteric energy was conducted taking into consideration two behaviours for the unloading cycles. The first one corresponds to an unloading oriented to the origin, in which $\beta$ presents a value of 1 , whereas the second one corresponds to an unloading with the initial stiffness, in which $\beta$ equals to 0 . It is worth noting that the models with $500 \mathrm{kN}$ of axial load were selected for this purpose. The axial load applied at the beginning of the analyses was obtained from an equivalence of the mass located at the top of the panel.

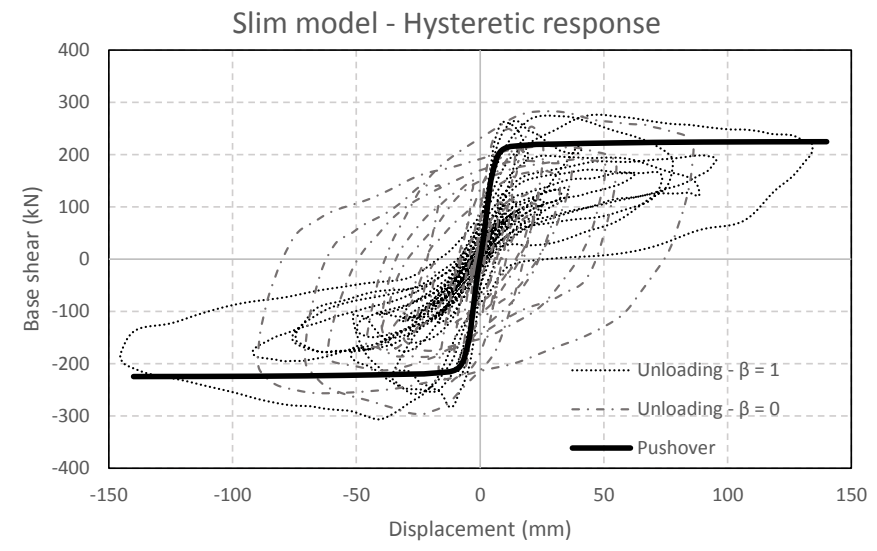

Figure 11. Hysteretic response of the slim model

In the case of the slim model, the hysteretic response considering the two different unloading behaviours (origin oriented and based on the initial stiffness) is illustrated in Figure 11. It can be ob- served that the response of this model presents a higher maximum top displacement with an unloading oriented to the origin presenting an approximate value of $145 \mathrm{~mm}$, whereas a value of $96 \mathrm{~mm}$ was obtained with initial stiffness unloading. On the other hand, it is possible to evidence that the base shear capacity is not influenced by the cyclic response but the material properties together with the backbone curve, presenting a value of $295 \mathrm{kN}$.

Figure $12 \mathrm{a}, \mathrm{b}$ illustrate the response of the base shear capacity and the top displacement of the slim model due to the dynamic loading. It was also observed from the base shear response that the model reaches a similar maximum value when using the different unloading conditions. In the case of the top displacement response, it is possible to identify that when defining an unloading oriented to the origin, the top displacement presents a maximum value higher than the corresponding one obtained with an initial stiffness unloading.

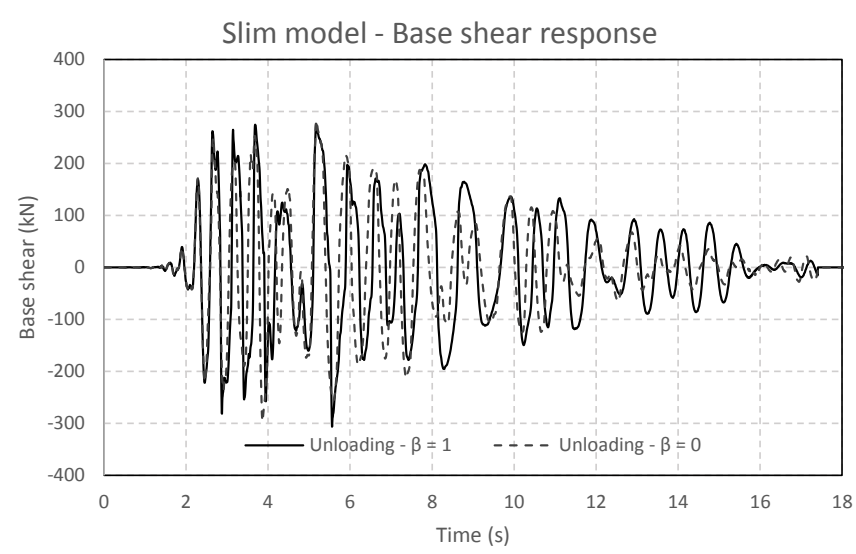

(a)

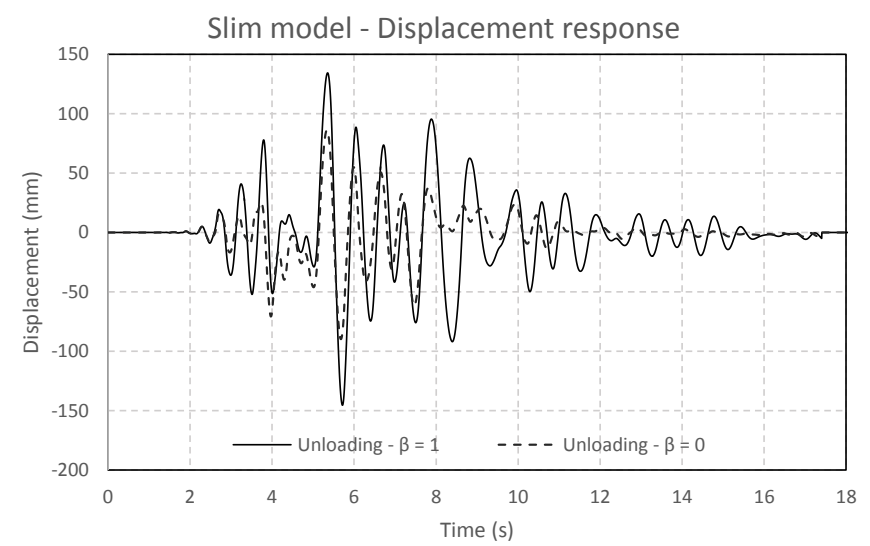

(b)

Figure 12. Dynamic response of the slim model in terms of (a) base shear capacity and (b) top displacement.

The hysteretic response of the squat model, which is governed by a shear failure mechanism, is illustrated in Figure 13. It is possible to evidence the influence on the cycles in terms of maximum displacement. In this case, the maximum absolute displacements presents approximate values of $80 \mathrm{~mm}$ and $25 \mathrm{~mm}$ corresponding to the origin ori- 
ented and initial stiffness unloading, respectively. Furthermore, it can be observed that the shear base capacity follows the same pattern as the slim model since its response does not depend on the cyclic response but on the axial load due to the MohrCoulomb criteria (approximate value of $400 \mathrm{kN}$ )

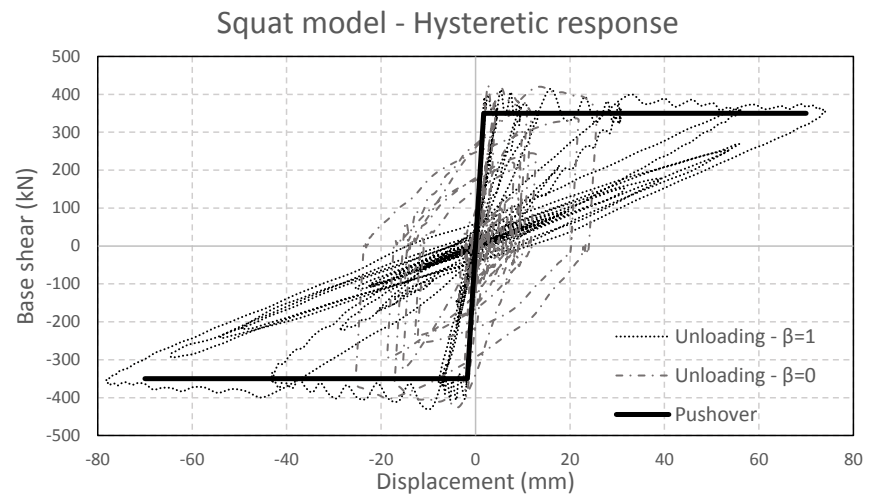

Figure 13. Hysteretic response of the squat model

The response of the base shear and top displacement during the analyses are illustrated in Figure $14 \mathrm{a}, \mathrm{b}$. In this case, these responses present a better agreement in terms of base shear capacity between the two different unloading conditions. However, this latter behaviour presents a significant influence on the top displacement response of the squat panel.

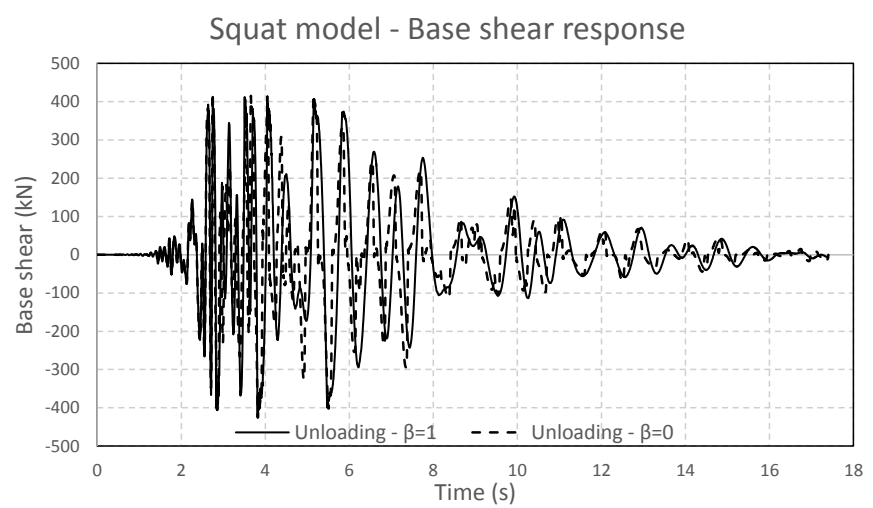

(a)

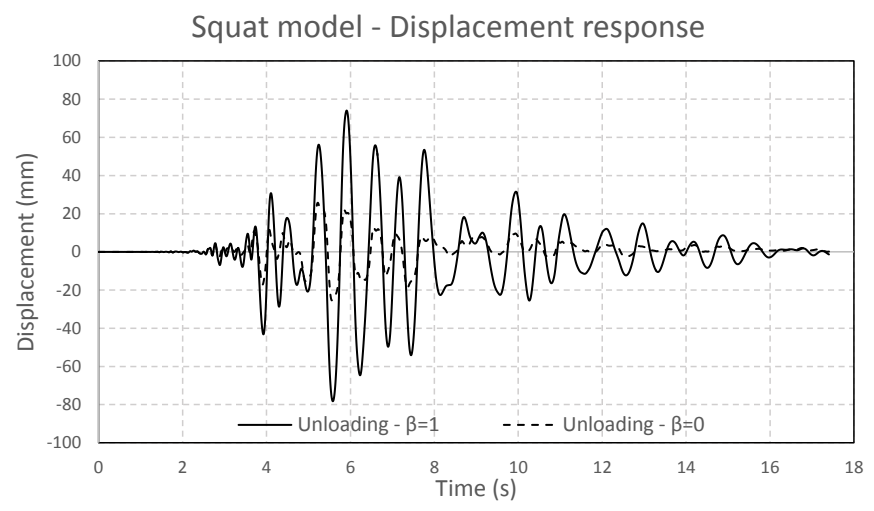

(b)

Figure 14. Dynamic response of the squat model in terms of (a) base shear capacity and (b) top displacement.
Finally, an assessment of the total dissipated energy due hysteresis has been conducted throughout the entire analyses. Figure 15 shows the cumulated dissipated energy plus the current elastic energy. It can be evidenced that the total dissipated energy is greater when the unloading stiffness is equal to the initial stiffness $(\beta=0)$. In the case of the slim model there is a $28.5 \%$ of reduction of the total energy dissipated which can be observed in the cyclic loops from the hysteretic response in Figure 11. In the case of the squat model, this reduction reaches a value of $27.2 \%$ presenting a similar behaviour.

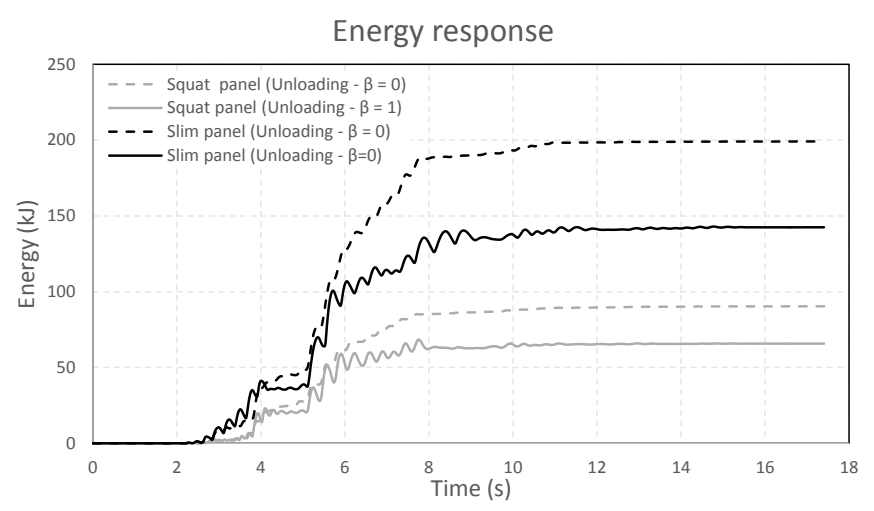

Figure 15. Hysteretic response of the squat model

\section{FINAL CONSIDERATIONS}

The nonlinear dynamic response of Unreinforced Masonry URM structures is a complex task mainly due to the uncertain and degrading behaviour of the material during the different cycles of a ground motion. Due to this complexity, this type of response has not yet been fully understood by the scientific community and the nonlinear dynamic numerical simulation of a URM structure still constitutes a challenging problem whose applications appear to be limited to the academic context.

In the engineering practice some simplified approaches, based on macro-element strategy, have been successfully applied in the nonlinear static context. However the proposed procedures do not allow to consider the hysteric behaviour typical of the dynamical response of URM structures.

In this preliminary investigation a plane macroelement, able to describe the nonlinear in-plane response of URM walls, is applied for simulating the nonlinear dynamic response of some simple URM panels under different loading and unloading conditions and assuming different constitutive laws for each fundamental failure mode. The obtained results, although representing a work in progress, clearly show up the need of defining suitable cyclic constitutive laws before proceeding to any nonlinear dynamic analysis of URM structure. 


\section{ACKNOWLEDGE}

The first author gratefully acknowledges the financial support of the Peruvian Institution InnóvatePerú through the PhD grant BECA-1-P-078-13.

\section{REFERENCES}

BRENCICH, A., GAMBAROTTA, L. \& LAGOMARSINO, S. (1998) A macroelement approach to the threedimensional seismic analysis of masonry buildings. 11th European Conference on Earthquake Engineering. Paris.

CALIÒ, I., MARLETTA, M. \& PANTÒ, B. (2012) A new discrete element model for the evaluation of the seismic behaviour of unreinforced masonry buildings. Engineering Structures, 40, 237-338.

D'ASDIA, P. \& VISKOVIC, A. (1996) Analisi tridimensionale della resistenza di edifici in muratura, storici o recenti, soggetti ad azioni orizzontali di tipo sismico. Convegno Nazionale La meccanica delle murature tra teoria e progetto. Messina.

HISTRA S.R.L (2015) HiStrA (Historical Structure Analysis) Release 17.2.3. Catania, Italy.

LOURENÇO, P. B. (1996) Computational strategies for masonry structures. Delft University, Delft, The Netherlands.

MAGENES, G. \& DELLA FONTANA, A. (1998) Simplified non-linear seismic analysis of masonry buildings. Proc Br Masonry Soc, 8.

MENDES, N. \& LOURENÇO, P. B. (2014) Sensitivity analysis of the seismic performance of existing masonry buildings. Engineering Structures, 80, 137-146.

TAKEDA, T., SOZEN, M. A. \& NIELSEN, N. N. (1970) Reinforced concrete response to simulated earthquakes. Journal of the Structural Division, 96, 2557-2573.

TNO (2013) DIANA - DIsplacement method ANAlyser. Release 9.4, User's Manual. TNO DIANA BV, Delft. 